\title{
A study on the effects of video games on social interaction among students belonging to the age group of 16-21 years
}

\author{
Tanvi D. Ail ${ }^{1}$, Dhyana Sara Jacob², Rafa Sultana ${ }^{3}$, Adira Raj ${ }^{4}$, Munawira P. ${ }^{5}$ \\ UG - Bachelor of Arts, St. Agnes College, Mangalore, Karnataka ${ }^{1-5}$
}

\begin{abstract}
Physical games, both indoor and outdoor, play a major role in the formation of friendships amongst children and adolescents. But today, this form of play has been replaced by video games, where the relationships are often built through the computer/mobile screens, and this is especially true in the case of multiplayer video games. They have become a means for gamers to meet new and like-minded people. For instance, since the pandemic, the number of hours that gamers have spent gaming has increased considerably and the number of people who have played video games for the first time has also gone up. One of the reasons for this could be the very fact that these games help us build new relationships that could go on to be lasting, particularly due to the shared interests and the sense of belonging and community that they offer.
\end{abstract}

This study was done with the goal of better understanding the impacts of video games' growing influence on younger generations. The focus of this paper is to study the effect that video games can have on social interactions, exclusively amongst students belonging to the age group of 16-21 years. Its goal is to raise awareness of the beneficial aspects of video games that are often overlooked, as well as to examine if they influence player behavior and, if so, to study these changes in behavior, with a focus on social interaction. A survey has been conducted to determine the same.

We have also suggested measures to help and prevent people from crossing the line between recreation and addiction because, an innovation made for boredom could turn into an addiction, if not controlled.

The null hypothesis is that there is no substantial difference in social interaction between gamers and non-gamers.

Key words: Video Games, Social Interaction, Students

\section{INTRODUCTION}

A video game is a game in which graphics generated by a computer programme are electronically manipulated and displayed on a monitor or other display. These games were initially introduced in the 1950s. But it wasn't until the 1980s that they actually became accessible to the general public. Nickson refers to this period as "the Golden Age of Arcade Gaming," which began with the release of 'Space Invaders' and continued with the production of a number of additional games, including 'Pacman.' Because computers were still in their infancy, gamers flocked to arcades to play these games. These arcades were also a means for people to physically interact with each other and meet new people.

But as mobile/computer games become more accessible and popular, this physical social contact could, allegedly, be at risk. The main issue that people have with video games is their concern that video games may raise the likelihood of aggression, antisocial conduct, a lack of social skills, negative impacts on IQ and memory, stress, a lack of enthusiasm for other pursuits, adverse effects on education and relationships and other such effects on mental and physical health. However, studies have repeatedly shown that, within a specific limit, video games do not produce such damages. But as there is reduced in-person interaction, there is increased concern regarding the implications of gaming on social interactions. As human beings are 'social animals,' social interactions form an integral aspect of human life, with ramifications that can be seen in every element of our development. As a result, it is critical to set clear boundaries when it comes to the effects of gaming on social interaction.

The introduction of multiplayer video games, nonetheless, has lent new facets to video games with reference to social interaction. One of the reasons for this could be the very fact that these games help us build new relationships (contrary to the popular belief), that could go on to be lasting, particularly due to the shared interests and the sense of belonging and community that they offer.

This survey assesses five domains of social interaction, I.e., socialization, communication, self, relationship and attitude. 1. Socialization: The act of mixing socially with others is referred to as socialization. This domain assesses the impact of video games on people's behavior in settings that necessitate socializing. 
2. Communication: Communication is the process of conveying or exchanging information through speech, writing, or any other medium. This area is used to evaluate the extent to which video games influence interpersonal interactions.

3. Self: The domain of self measures the idea that the individuals have about the kind of person they are. When individuals get addicted to video games, they start identifying themselves with the characters in the game and could lose their sense of identity.

4. Relationship: The way two or more people or groups regard and behave towards one another is referred to as a relationship. This domain is further divided into two categories- friends and family. The impact of video games on people's relationships with their friends and family is examined under this domain.

5. Attitude: An attitude refers to a set of emotions, beliefs, and behaviors toward a particular object, person, thing, or event. Attitudes are often the result of experience or upbringing, and they can have a powerful influence over behavior. This area primarily assesses the impact of video games on aggression.

\subsection{Objectives}

- The major objective of this study is to determine the effect of video games on social interaction among students belonging to the age group of 16-21 years.

- The study also focuses on determining the level of impact of video games on the domains of socialization, communication, relationship with reference to family and friends, self and attitude.

\subsection{Null Hypothesis:}

There is no substantial difference in social interaction between gamers and non-gamers.

\section{METHODOLOGY}

The survey method was used to collect the primary data to study the effects of video games on social interaction. This study was done exclusively on the students between the age group of 16-21 years. They were asked 25 dichotomous questions, which are grouped into five domains, namely socialization, communication, relationship, self and attitude. The relationship domain has two sub-categories, I.e., family and friends.

Sample - A total of 100 students were included in the study, 33 of whom were non-gamers and 67 were gamers.

The survey had 25 questions, with 4 questions being positive and 20 questions being negative. For positive questions, yes responses received a score of 0 and no responses received a score of 1 , and vice versa for negative questions. One question was used to categorize the gamers and non-gamers.

\section{RESULTS AND DISCUSSION}

3.1. Table 1 showing the mean scores of gamers and non-gamers in the five domains of social interaction. Table.1.

\begin{tabular}{|l|l|l|}
\hline Domains & Mean score of gamers & Mean score of non-gamers \\
\hline Socialization & 2.208 & 2.242 \\
\hline Communication & 1.552 & 1.818 \\
\hline Self & 1.373 & 0.212 \\
\hline Relationship & 2.776 & 2.333 \\
\hline Attitude & 1.194 & 0.242 \\
\hline
\end{tabular}

In the domain of communication, there were four questions, out of which two were positive and two were negative. According to the data, video games have had a positive impact on the gamers as compared to the non-gamers. This is because gaming has given people more opportunities to meet like-minded people and make friends.

The domain of self, had five questions with all of them being negative. The mean scores reveal a significant difference in self-perception between gamers and non-gamers. This proves that gaming has had a negative impact on the gamers. There were eight questions in the relationship domain, two of which were positive and six of which were negative. The difference between the mean score of gamers and non-gamers in this domain is minor, depicting low to no impact of video games on this domain.

There were four negative questions in the domain of attitude. And the data shows a significant difference in the mean scores of gamers and non-gamers. This demonstrates that video games have a negative impact on people's attitudes.

The results are influenced by several factors such as subjective mood, age of exposure to video games, genre of games played, peer influence, home environment and other physical and mental conditions. 


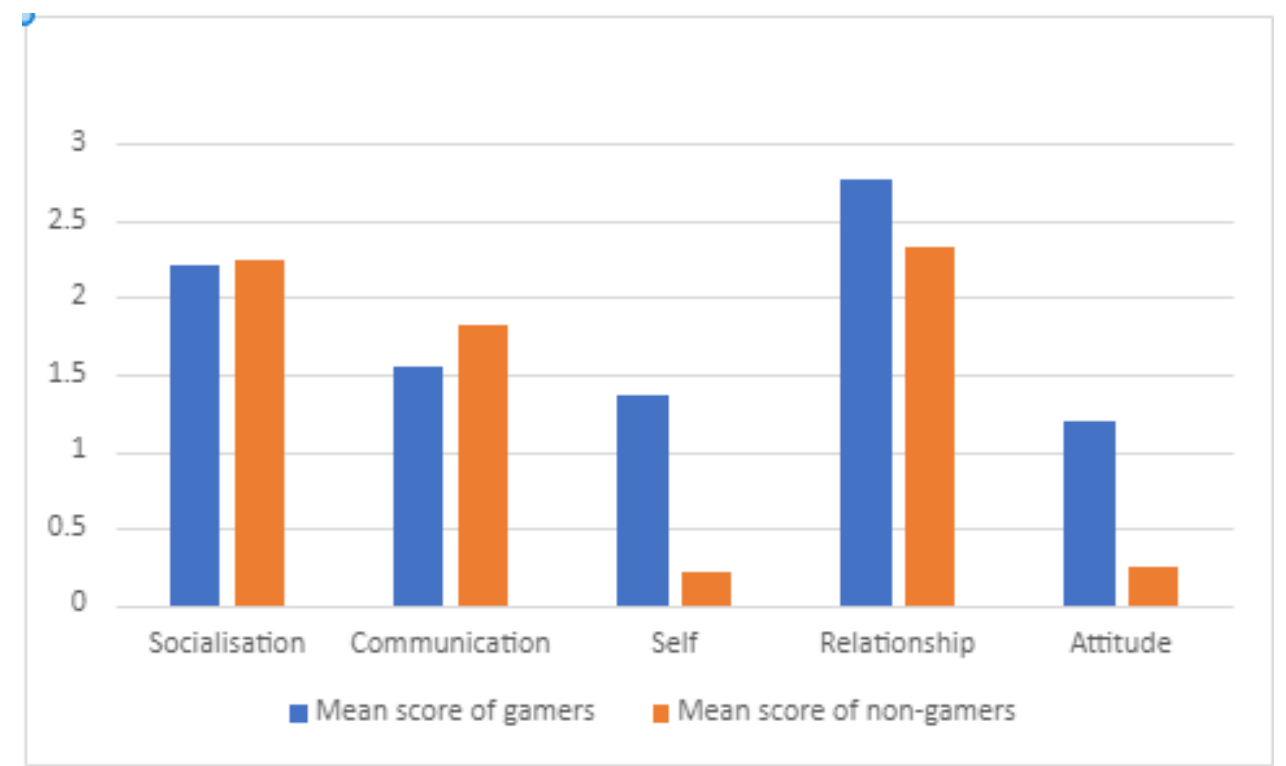

Fig.1. Mean score of gamers and non-gamers in each domain

Table 1 shows the mean scores of gamers and non-gamers in the five domains of social interaction. There were eight questions in the socialization domain, with three of them being positive and five negative. However, the mean scores showed no variation in their socialization. This shows that video games had no negative impact on this domain.

3.2. Table 2 showing the mean scores of gamers and non-gamers in the relationship domain.

Table.2.

\begin{tabular}{|l|l|l|}
\hline Relationship & Mean score of gamers & Mean score of non-gamers \\
\hline Friends & 1.86 & 2.54 \\
\hline Family & 0.910 & 0.03 \\
\hline
\end{tabular}

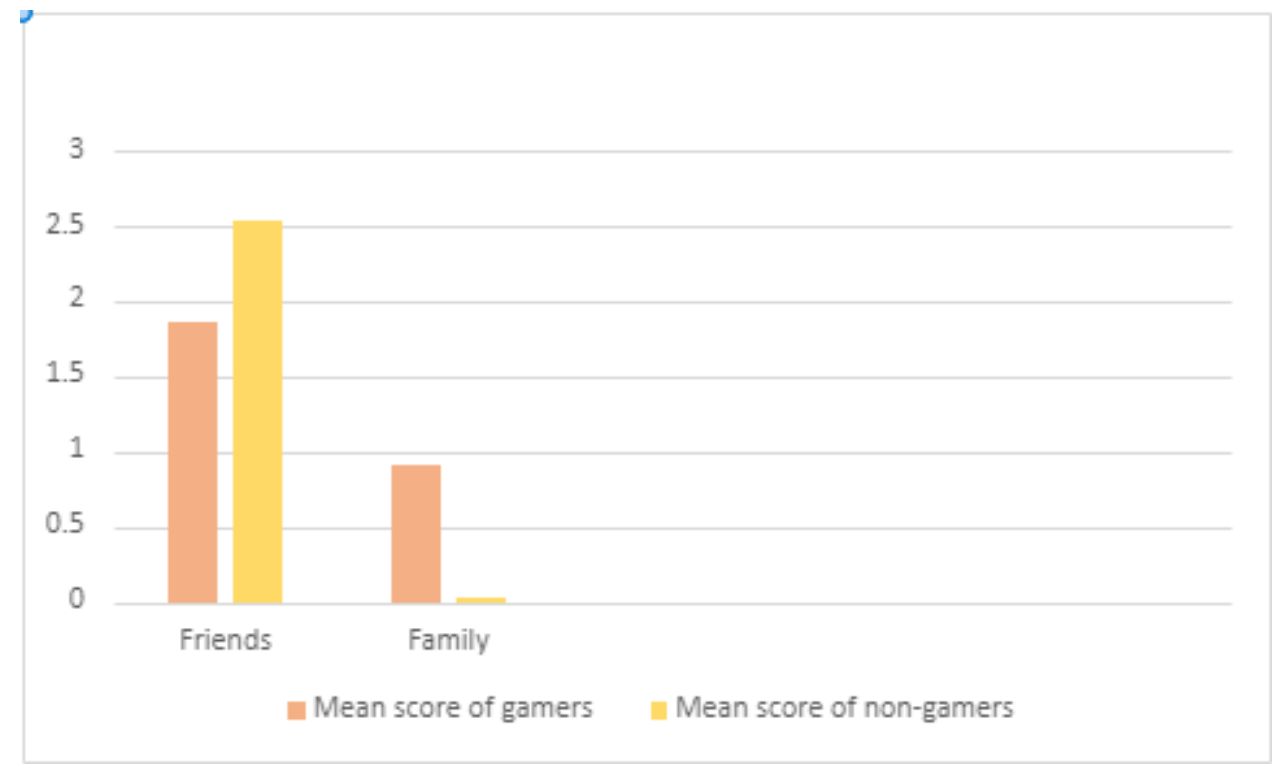

Fig.2. Mean scores of gamers and non-gamers in the relationship domain

The relationship domain was further divided into two sub-categories of friends and family, which is depicted in Table 2 . Gaming has had a positive impact on the gamer's relationship with respect to their friends. This is due to the gamers' suggestion that gaming has had no negative impact on their social circle. On the other hand, it has had a negative impact on their relationship with their families. 
DOI: $10.17148 / I J A R C C E .2022 .11141$

3.3. Statistical Analysis

\begin{tabular}{|l|l|l|l|l|r|r|}
\hline Groups & N & M & Sig & SD & $t$ & $t_{\alpha}$ \\
\hline Gamers & $\mathbf{6 7}$ & $\mathbf{7 . 6 5 6}$ & $\mathbf{1 1 1 3 . 6 3}$ & $\mathbf{4 . 0 7 6}$ & $\mathbf{4 . 7 8 6}$ & $\mathbf{2 . 6 3}$ \\
\cline { 1 - 1 } $\begin{array}{l}\text { Non- } \\
\text { Gamers }\end{array}$ & 33 & 4.151 & $\mathbf{8 2 . 2 4 2}$ & 1.578 & & \\
\hline
\end{tabular}

Interpretation - Since the calculated ' $t$ ' Is more than ' $t_{\alpha}$,' we reject the null hypothesis. This leads us to accept the alternative hypothesis, proving that there is a substantial difference in the social interaction between gamers and nongamers.

\section{CONCLUSION}

The preceding research and findings have shown that video games have had an impact on some aspects of social interactions of the subjects who were gamers.

Video games have had a discernible unfavorable impact on some parts of social interactions of the subjects who were gamers, according to the areas of self, relationship, and attitude. However, a positive impact is seen in the area of friendship, whereas there is a negative impact in the family area. This shows that video games have had both positive and negative impact on social interaction among gamers.

\section{REFERENCES}

1. Cole, H., \& Griffiths, M. D. (2007). Social interactions in massively multiplayer online role-playing games. Cyberpsychology \& Behavior, 10, 575-583.doi:10.1089/cpb.2007.9988.

2. de Freitas, S., \& Griffiths, M. D. (2008). Massively multiplayer online role-play games for learning. In Fording, R. E. (Ed.), Handbook of research on effective electronic gaming in education (pp. 51-65). Hershey, PA: Information Science Reference.doi:10.4018/978-1-59904-808-6.ch003.

3. Lo, S., Wang, C., \& Fang, W. (2005). Physical interpersonal relationships and social anxiety among online game players. Cyberpsychology \& Behavior, 8, 15-20.doi:10.1089/cpb.2005.8.15.

4. Turkle, S. (2011). Alone together: Why we expect more from technology and less from each other. New York, NY: Basic Books.

5. Drotner, K., \& Livingstone, S. (Eds.). (2008). International handbook of children, media and culture. London, UK: Sage

6. Yee, N. (2007) the psychology of massively multi-user online role-playing games: Motivations, emotional investment, relationships and problematic usage. In Schroder, R., \& Axelsson, A. (Eds). Avatars at work and play: Collaboration and Interaction in shared virtual environments (pp.187-207). London, UK: Springer.

7. Rosengren, K. E. (2014). Media effects and beyond: Culture, socialization and lifestyles. London, UK: Routledge.

8. Whang, L. S., \& Chang, G. (2004). Lifestyles of virtual world residents: Living in the online game "lineage." Cyberpsychology \& Behavior, 7, 592-600.

9. Utz, S. (2000). Social information processing in MUDs: The development of friendships in virtual worlds. Journals of Online Behavior, I (1).

10. Griffiths, M. D. (1997). Computer game playing in early adolescence. Youth \& Society, 29, 223-237.doi: 10.1177/0044118X97029002004

11. Griffiths, M. D., \& Davies, M. N. O. (2005). Videogame addiction: Does it exist? In Goldstein, J., \& Raessens, J., (Eds), Handbook of computer game studies (pp.359-368). Cambridge, MA: MIT Press.

12. Griffiths, M. D., Davies, M. N. O., \& Chappell, D. (2003). Breaking the stereotype: The case of online gaming. Cyberpsychology \& Behavior, 6, 81-91.doi: 10.1089/109493103321167992

13. Griffiths, M. D., \& Hunt, N. (1998). Dependence on computer games by adolescents. Psychological Reports, 82 , 475-480.

14. Grusser, S. M., Thalemann, R., \& Griffiths, M. D. (2007). Excessive computer game playing: Evidence for addiction and aggression? Cyberpsychology \& Behavior, 10, 290-292.doi:10.1089/cpb.2006.9956

15. Lo, S., Wang, C., \& Fang, W. (2005). Physical interpersonal relationships and social anxiety among online game players. Cyberpsychology \& Behavior, 8, 15-20.doi:10.1089/cpb.2005.8.15

Mrs. Vinatha K.

\section{ACKNOWLEDGEMENTS}

Associate Professor, Dept. Of Psychology, St. Agnes College (Autonomous)

Dr. Hithakshi B.

HOD \& Assistant Professor, Dept. Of Psychology, St. Agnes College (Autonomous) 